\title{
Solvent free hydroxylation of the methyl esters of Blighia unijugata seed oil in the presence of cetyltrimethylammonium permanganate
}

\author{
Adewale Adewuyi ${ }^{1,2^{*}}$, Rotimi A Oderinde ${ }^{3}$, BVSK Rao $^{2}$, RBN Prasad $^{2}$ and M Nalla ${ }^{2}$
}

\begin{abstract}
Extraction of oil from the seed of Blighia unijugata gave a yield of $50.82 \pm 1.20 \%$ using hexane in a soxhlet extractor. The iodine and saponification values were $67.60 \pm 0.80 \mathrm{~g}$ iodine/100 $\mathrm{g}$ and $239.20 \pm 1.00 \mathrm{mg} \mathrm{KOH} / \mathrm{g}$ respectively with C18:1 being the dominant fatty acid. Unsaturated methyl esters of Blighia unijugata which had been previously subjected to urea adduct complexation was used to synthesize methyl 9, 10dihydroxyoctadecanoate via hydroxylation in the presence of cetyltrimethylammonium permanganate (CTAP). The reaction was monitored and confirmed using FTIR and GC-MS. This study has revealed that oxidation reaction of mono unsaturated bonds using CTAP could be achieved under solvent free condition.
\end{abstract}

\section{Introduction}

The replacement of petrochemicals by oleochemical feedstocks in many industrial and domestic applications as resulted in increase in demand for bio-based products and as such recognizing and increasing the benefits of using renewable materials. This has reduced the dependence on imported petroleum and promoted the sustainable agricultural initiative. Vegetable oils are one of the most versatile renewable substrates and can be converted into several products [1-3]. The use of lesser known seed oils is of great benefit in this regards, example of such lesser known underutilized seed oil is that of Blighia unijugata.

Blighia unijugata is a tree planted as shade tree in Nigeria. It is of attractive appearance especially when in fruit which are red or pinkish yellow. The wood is used for buildings; it is also recognized for its sedative and analgesic properties in treatment of rheumatism [4]. Presently, the seed oil has no specific use in Nigeria as the seeds are discarded as waste.

Natural polyols can be obtained by chemical modification of the vegetable oils introducing hydroxyl groups in an unsaturated triglyceride by hydroxylation of carboncarbon double bonds and/or by alcoholysis of the

\footnotetext{
* Correspondence: walexy62@yahoo.com

'Department of Chemical Sciences, Redeemer's University, Mowe, Ogun state, Nigeria

Full list of author information is available at the end of the article
}

triglyceride to obtain mainly a monoglyceride $[3,5]$. Vegetable oil contains mixture of different unsaturated and saturated fatty acids in varying amounts; these have different applications, though, there is little or scanty report on their isolation.

Urea complexation reaction is a well-established technique for elimination of saturated and monounsaturated fatty acids [6-9]. Urea complexation has the advantage that complexed crystals are extremely stable, and filtration does not necessarily have to be carried out at the very low temperatures which solvent crystallization of fatty acids would require. This method is also favorable because complexation depends upon the configuration of the fatty acid moieties due to the presence of multiple double bonds, rather than pure physical properties such as melting point or solubility [10]. The saturated and monounsaturated fatty acids easily complex with urea and crystallize out on cooling and may subsequently be removed by filtration. The liquid or non-urea complexed fraction is enriched with unsaturated fatty acids.

The fundamentally attractive concept of green Chemistry is solvent free reactions. Solvent-free reactions are an interesting alternative approach, mainly when these conditions eliminate the use of a solid support or solvent from the reaction [11]. A dry solid-phase reaction is solvent-free, also a reaction where there is liquid presence, but not acting as a solvent (i.e. nothing is dissolved in it) is also solvent-free" [12]. The economic 
benefits of green Chemistry are central drivers in its advancement. Industry is adopting green Chemistry methodologies because they improve the corporate bottom line. A wide array of operating costs is decreased through the use of green Chemistry. When less waste is generated, environmental compliance casts go down and when waste is eliminated treatment and disposal become unnecessary. Decreased solvent usage and fewer processing steps lessen the material and energy costs of manufacturing and increase material efficiency.

Permanganate, an important oxidant in many organic and inorganic redox reactions, involves the Mn (VII) entity, which is renowned for its versatility. The permanganate oxidation process is eco-friendly and has gained importance in green Chemistry. Cetyltrimethylammonium permanganate (CTAP) possess a long hydrocarbon chain that can draw substrate close to $\mathrm{MnO}_{4}{ }^{-}$ion in a micelle-like aggregation, thereby enabling reactant molecules to efficiently interact with oxidizing ion even if a homogenizing solvent is not present. This attribute pointed our attention to the hydroxylation of olefin bonds in the unsaturated methyl esters from seed oil of Blighia unijugata with cetyltrimethylammonium permanganate. In the present study, the seed oil of Blighia unijugata was chemically characterized, the unsaturation of the methyl ester was increased using urea adduct complexation reaction and 9,10-dihydroxyoctadecanoate was synthesized from the unsaturated methyl esters using cetyltrimethylammonium permanganate.

\section{Materials and method}

Extraction and chemical analysis of the seed oil of Blighia unijugata

The dried seeds of Blighia unijugata were extracted with $n$-hexane for $10 \mathrm{hr}$ using soxhlet extractor [13]. The oil was analyzed for iodine, saponification and free fatty acid content by method described by the Association of Official Analytical Chemist [14].

\section{Fatty acid composition of Blighia unijugata}

Fatty acid methyl esters of the oil were prepared by refluxing the sample at $70^{\circ} \mathrm{C}$ for $3 \mathrm{~h}$ in $2 \%$ sulphuric acid in methanol. The esters were extracted into ethyl acetate, washed free of acid and passed over anhydrous sodium sulphate. The ethyl acetate extracts were further concentrated using a rotary evaporator. The fatty acid composition was analyzed using an Agilent $6890 \mathrm{~N}$ series gas chromatography equipped with FID detector on a split injector. A fused silica capillary column (DB-225, $30 \times 0.32$ m i.d., J \& W Scientifics, USA) was used with the injector and detector temperature maintained at $230^{\circ} \mathrm{C}$ and $250^{\circ} \mathrm{C}$ respectively. The oven temperature was programmed at $160^{\circ} \mathrm{C}$ for $2 \mathrm{~min}$ and finally increased to $230^{\circ} \mathrm{C}$ at $4^{\circ} \mathrm{C} / \mathrm{min}$. The carrier gas was nitrogen at a flow rate of $1.5 \mathrm{~mL} / \mathrm{min}$. The area percentages were recorded with a standard Chemstation Data System.

\section{Urea adduct complexation reaction of Blighia unijugata methyl esters}

Fatty acid methyl esters for the urea adduct complexation reaction were prepared by refluxing the oil at $70^{\circ} \mathrm{C}$ for $3 \mathrm{~h}$ in $1 \% \mathrm{KOH}$ in methanol. The esters were extracted into ethyl acetate, washed free of acid and passed over anhydrous sodium sulphate. The ethyl acetate extracts were further concentrated using a rotary evaporator. Methyl esters (100 g) were dissolved in methanol $(1000 \mathrm{ml})$ to which urea $(200 \mathrm{~g})$ had been added. The mixture was warmed with stirring until the whole mixture turned into a clear homogeneous solution [15]. The solution was allowed to cool to room temperature and kept refrigerated at $5^{\circ} \mathrm{C}$ for $8 \mathrm{~h}$. Crystals were removed by filtering through a Buchner funnel to remove the urea complexes, which were washed twice with $25 \mathrm{ml}$ of methanol saturated with urea. The filtrate which is rich in unsaturated methyl esters was poured into $1 \%$ hydrochloric acid $(600 \mathrm{ml})$ and extracted alternatively with hexane and diethyl ether. The combined organic layers were washed with water twice (50 $\mathrm{ml}$ ) and passed over anhydrous sodium sulphate and later concentrated using a rotary evaporator. This reaction was repeated changing the ratio of fatty acid methyl esters to urea from $1: 2$ to $2: 1$ in order to further increase the unsaturation of the methyl esters. The resulting methyl esters (BME) were then taken for the determination of the constituent fatty acids using a GC as described above.

\section{Preparation of cetyltrimethylammonium permanganate}

This was achieved by introducing a solution of 27.0 mmol of $\mathrm{KMnO}_{4}$ (4.25 g in $25 \mathrm{ml}$ distilled water) into a $250 \mathrm{ml}$ two-necked round bottom flask in a water bath maintained at $8^{\circ} \mathrm{C}$. After about $15 \mathrm{~min}$, solution of 25.0 mmol of cetyltrimethylammonium bromide $(9.10 \mathrm{~g}$ in $50 \mathrm{ml}$ dichloromethane) was added into the flask and stirred for $4 \mathrm{~h}$. The organic layer was separated and the solvent recovered under reduced pressure with the crystalline cetyltrimethylammonium permanganate (purple coloured) precipitating out before the complete recovery of the solvent; it was filtered, washed with distilled water and ether and dried over $\mathrm{P}_{2} \mathrm{O}_{5}$ under vacuum.

\section{Dihydroxylation of BME using cetyltrimethylammonium permanganate}

The dihydroxylation was carried out in a clamped three necked round bottom flask equipped with a thermometer and a stirrer in a thermo-regulated water bath. 
About $2.10 \mathrm{~g}(5.2 \mathrm{mmol})$ of cetyltrimethylammonium permanganate with five drops of distilled water was introduced into the flask. About $5.0 \mathrm{mmol}$ of BME was slowly added drop wise while stirring the mixture. The mixture was stirred for $1 \mathrm{~h}$ and extracted three times with $50 \mathrm{ml}$ portion of ether; this was later washed with saturated solution of $\mathrm{NaCl}$, dried over $\mathrm{Na}_{2} \mathrm{SO}_{4}$ and concentrated on a rotary evaporator.

\section{Isolation of methyl 9, 10-dihydroxyoctadecanoate}

The final product was separated on a $1 \mathrm{~g}$ scale by silica gel column chromatography using a glass column $20 \mathrm{~cm}$ $\times 2 \mathrm{~cm}$ OD packed with $30 \mathrm{~g}$ activated silica gel (60-120 mesh). Hydrocarbons and other non-polar compounds were eluted with petroleum ether (boiling point, $60-80^{\circ}$ C). The methyl 9, 10-dihydroxyoctadecanoate were eluted using a mixture of petroleum ether - diethyl ether $(40: 60 \mathrm{v} / \mathrm{v})$. The fractions were screened by TLC for the identification of the compounds isolated. The eluted spots were identified using iodine vapors.

\section{Trimethylsilylation derivatisation and GC-MS analysis of methyl 9, 10-dihydroxyoctadecanoate}

The isolated methyl 9,10-dihydroxyoctadecanoate was derivatised and identified by GC-MS analysis using Agilent (Palo Alto, USA) $6890 \mathrm{~N}$ gas chromatography equipped with an HP-1 MS capillary column connected to an Agilent 5973 mass spectrometer operating in the EI mode (70 ev; $\mathrm{m} / \mathrm{z} 50-550$; source temperature $230^{\circ} \mathrm{C}$ and quadruple temperature $150^{\circ} \mathrm{C}$ ). Methyl 9,10-dihydroxyoctadecanoate was silylated using $\mathrm{N}, \mathrm{O}$-Bis(trimethylsilyl) trifluoroacetamide; about $13 \mu \mathrm{l} / \mathrm{mg}$ of $\mathrm{N}$, O-Bis(trimethylsilyl)trifluoroacetamide was added to methyl 9,10dihydroxyoctadecanoate, kept at $75^{\circ} \mathrm{C}$ for $60 \mathrm{~min}$ and thoroughly shaken. The final product was extracted in ethyl acetate and concentrated using a rotary evaporator. Structural assignments were made based on interpretation of mass spectrometric fragmentation and confirmation by comparison of retention time as well as fragmentation pattern of authentic compounds and the spectral data obtained from the Wiley and NIST libraries.

\section{Fourier Transform Infrared (FTIR)}

The FTIR spectra of the methyl esters and hydroxylated methyl esters were recorded using a Perkin Elmer FTIR system spectrum BX LR64912C. The samples were spread over $\mathrm{NaCl}$ cells, and their spectra were recorded in the range of $4000-400 \mathrm{~cm}^{-1}$.

\section{Results and discussion}

Chemical characterization and fatty acid composition of the seed oil of Blighia unijugata

The result of the chemical characterization of Blighia unijugata is presented in Table 1. The oil yield from the seed of
Table 1 Characterization of the oil of B.unijugata

\begin{tabular}{ll}
\hline Parameter & B. unijugata \\
\hline Oil yield (\%) & $50.82 \pm 1.20$ \\
FFA (\%) & $7.00 \pm 0.1$ \\
lodine value (g iodine/100 g) & $67.60 \pm 0.80$ \\
Saponification value $(\mathrm{mg} \mathrm{KOH} / \mathrm{g})$ & $239.20 \pm 1.00$ \\
\hline
\end{tabular}

Values are mean \pm standard deviation of triplicate determinations.

Blighia unijugata was found to be $50.82 \pm 1.20 \%$. The iodine value and saponification were found to be $67.60 \pm$ $0.80 \mathrm{~g}$ iodine $/ 100 \mathrm{~g}$ and $239.20 \pm 1.00 \mathrm{mg} \mathrm{KOH} / \mathrm{g}$ respectively. These values are different from what was initially reported [16] which might be due to the presence of impurities or solvent contamination in the previously analyzed samples. The fatty acid composition is shown in Table 2 . The dominant fatty acid was found to be C18:1 (48.1 \pm $0.50 \%)$ while the least present was found to be C14:0 (0.2 \pm $0.10 \%)$. C16:0 was $34.5 \pm 0.20 \%$ while $\mathrm{C} 18: 0$ was $14.1 \pm$ $0.10 \%$ with a total unsaturation of $50.4 \pm 0.20 \%$. These data are available with the online version of this paper. Additional file 1 describes the characterization and fatty acid composition of the seed oil of Blighia unijugata.

\section{Urea adduct complexation reaction of Blighia unijugata methyl esters}

The urea adduct complexation reaction was carried out so as to increase the unsaturation of Blighia unijugata methyl esters. This increase in unsaturation allows the introduction of different functional groups in order to improve on the possible applications of the seed oil of Blighia unijugata. The effect of the complexation reaction on the methyl esters of Blighia unijugata is shown in Figure 1. After the complexation reaction C14:0, C18:0, C20:0 and C24:0 fatty acids were totally removed while the amounts of C16:0 saturated fatty acid was reduced. C16:0 was reduced from $34.5 \pm 0.20 \%$ to 4.73 $\pm 0.10 \%$. The unsaturation of the methyl esters was increased from $50.4 \pm 0.20 \%$ to $94.56 \pm 0.20 \%$ with a

Table 2 Fatty acid composition (wt \%) of B.unijugata

\begin{tabular}{ll}
\hline Fatty acids & B. unijugata \\
\hline $14: 0$ & $0.2 \pm 0.10$ \\
$16: 0$ & $34.5 \pm 0.20$ \\
$18: 0$ & $14.1 \pm 0.10$ \\
$18: 1$ & $48.1 \pm 0.50$ \\
$18: 2$ & $1.8 \pm 0.30$ \\
$18: 3$ & $0.3 \pm 0.20$ \\
$20: 0$ & $0.5 \pm 0.10$ \\
$20: 1$ & $0.2 \pm 0.00$ \\
$24: 0$ & $0.3 \pm 0.10$ \\
Unsaturated & $50.4 \pm 0.20$ \\
Saturated & $49.6 \pm 0.10$ \\
\hline
\end{tabular}

Values are mean \pm standard deviation of triplicate determinations. 

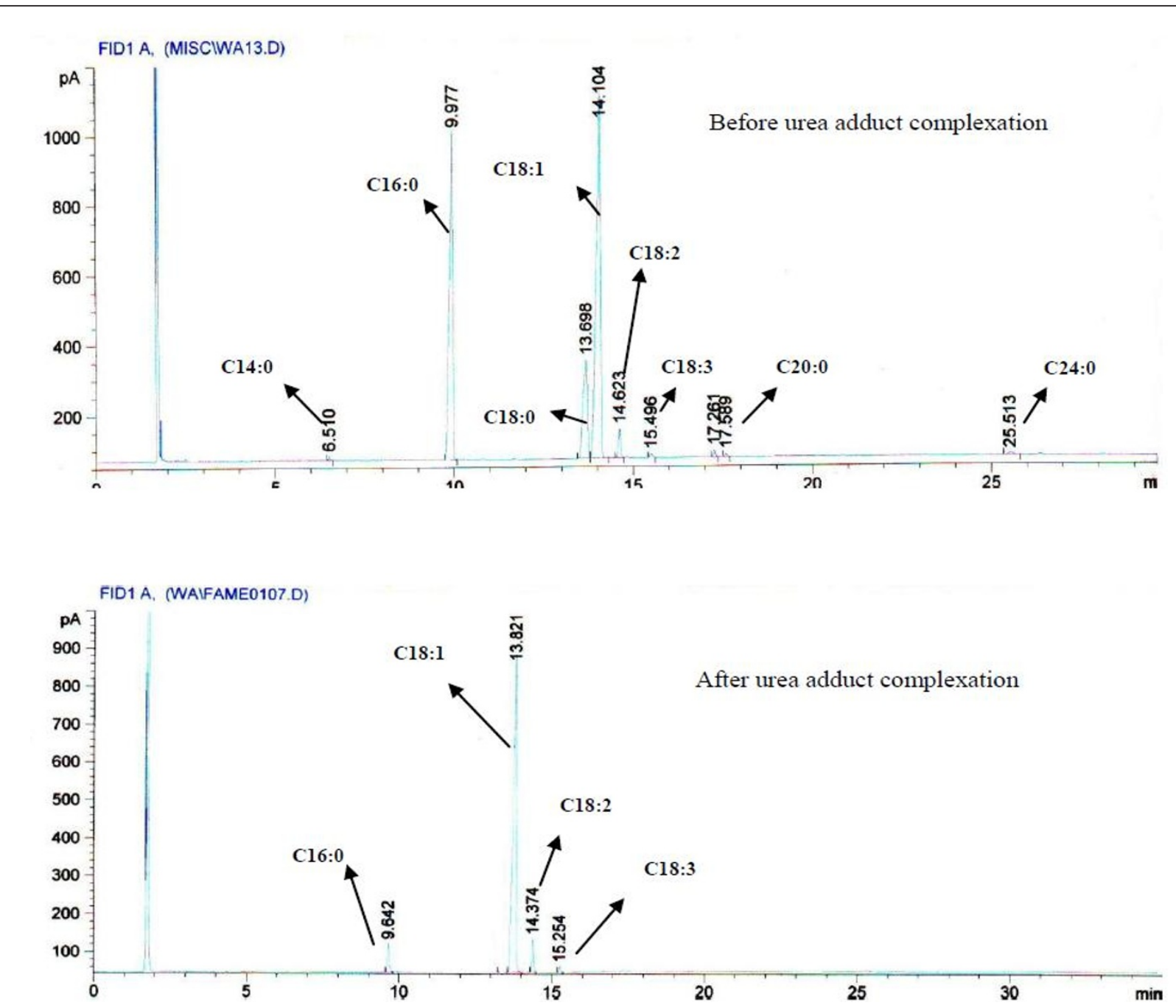

Figure 1 Fatty acid composition before and after urea adduct complexation reaction.

yield of $49.20 \pm 0.20 \%$. The amounts of C18:1 which was found as the dominant fatty acid in the oil was increased from $48.1 \pm 0.50 \%$ to $88.75 \pm 0.40 \%$. This increase in C18:1 and the fair percentage yield of $49.20 \pm 0.20 \%$ were the major indicators that led to the application of the methyl esters of Blighia unijugata in the synthesis of methyl 9, 10-dihydroxyoctadecanoate.

\section{Dihydroxylation of BME using cetyltrimethylammonium permanganate}

The synthesis of methyl 9, 10-dihydroxyoctadecanoate was achieved via dihydroxylation of the unsaturated methyl esters (BME) after urea adduct complexation. The reaction was monitored using TLC while the formation was confirmed using IR and GC-MS. The IR result if shown in Figure 2. The spectrum of the oil showed a peak at 3006 $\mathrm{cm}^{-1}$ which was assigned to the vibrational frequency of the $\mathrm{C}-\mathrm{H}$ stretching of $\mathrm{C}=\mathrm{C}-\mathrm{H}$ present in the oil. The $\mathrm{C}=$
O stretching frequency of ester functional groups was found at $1743 \mathrm{~cm}^{-1}$. The peak at $2927 \mathrm{~cm}^{-1}$ and $2853 \mathrm{~cm}^{-1}$ may be accounted for to be due to the $\mathrm{C}-\mathrm{H}$ stretching of $-\mathrm{CH}_{3}$ and $-\mathrm{CH}_{2}$ respectively. The values $1458 \mathrm{~cm}^{-1}$ and $1169 \mathrm{~cm}^{-1}$, could be attributed to the $\mathrm{C}-\mathrm{H}$ bending frequency of saturated alkane and $\mathrm{C}-\mathrm{O}$ stretching frequency of ester respectively. The spectrum of the hydroxylated methyl esters has a peak at 3404 which accounts for the presence of $\mathrm{OH}$ functional group. The peak at $3006 \mathrm{~cm}^{-1}$ which accounted for the presence of unsaturation in the methyl esters totally disappeared after hydroxylation suggesting the introduction of the $\mathrm{OH}$ functional into the methyl esters at the unsaturated carbon atoms (Figure 3).

\section{Isolation and GC-MS analysis of methyl 9, 10- dihydroxyoctadecanoate}

Pure methyl 9, 10-dihydroxyoctadecanoate was isolated on a $1 \mathrm{~g}$ scale with a yield of $85.10 \pm 0.70 \%$. The result 

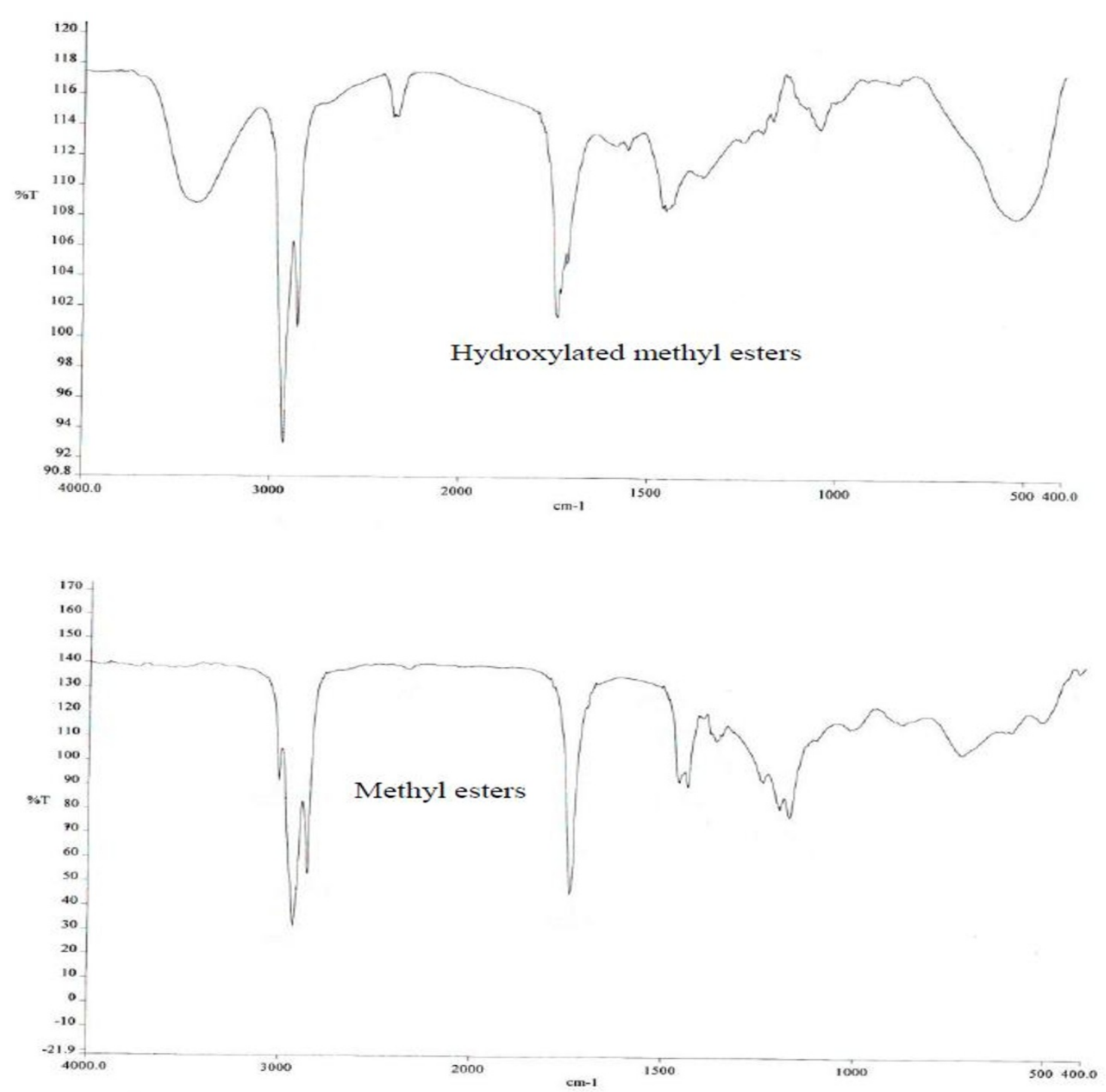

Figure 2 FTIR of the methyl esters and hydroxylated unsaturated methyl esters.

of the GC-MS is presented in Figure 4. The fragmentation pattern of the synthesized methyl 9, 10-dihydroxyoctadecanoate compared favorably with those of Wiley and NIST library.

\section{Conclusion}

Oil was extracted from the seed of Blighia unijugata using hexane in a soxhlet extractor. The iodine value was $67.60 \pm 0.80 \mathrm{~g}$ iodine $/ 100 \mathrm{~g}$ while the saponification

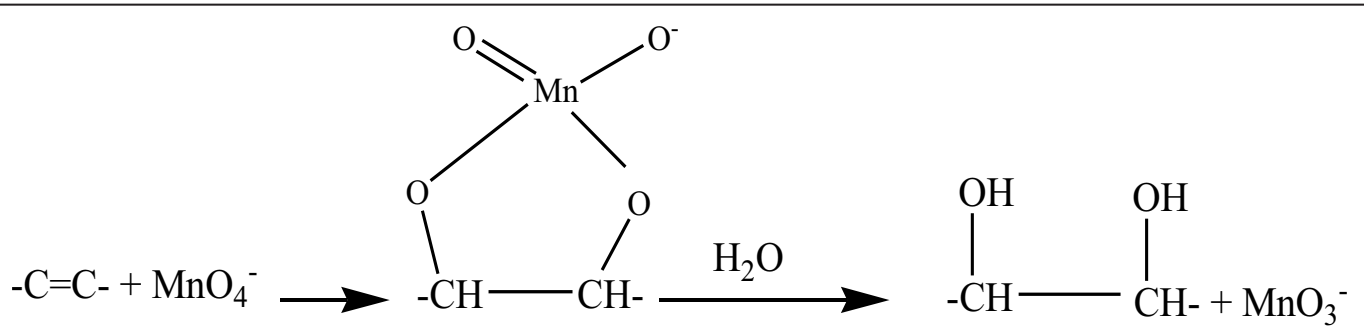

Figure 3 Reaction scheme for the production of methyl 9, 10-dihydroxyoctadecanoate. 


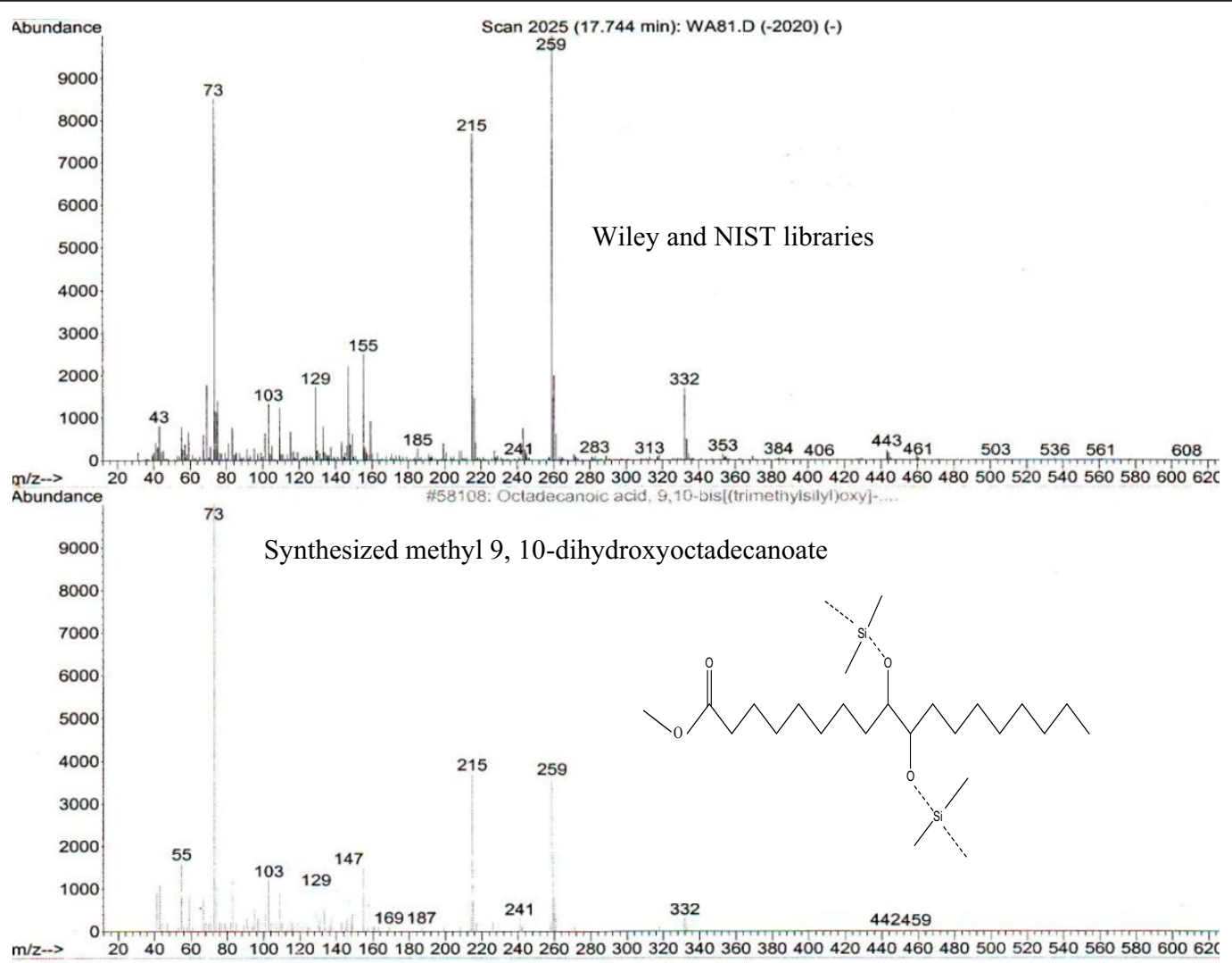

Figure 4 GC-MS analysis of methyl 9, 10-dihydroxyoctadecanoate.

value was $239.20 \pm 1.00 \mathrm{mg} \mathrm{KOH} / \mathrm{g}$. The dominant fatty acid was found to be C18:1. The unsaturation of the methyl esters of Blighia unijugata was increased using the urea adduct complexation reaction. Methyl 9, 10dihydroxyoctadecanoate was synthesized from the methyl esters via hydroxylation using cetyltrimethylammonium permanganate. The reaction was monitored and confirmed using FTIR and GC-MS. This study has revealed that oxidation reaction using CTAP do not require solvent medium and can be achieved under complete solvent free condition.

\section{Additional material}

Additional file 1: Characterization and fatty acid composition of Blighia unijugata seed oil. Additional file 1 describes the characterization and fatty acid composition of the seed oil of Blighia unijugata.

\section{Author details}

${ }^{1}$ Department of Chemical Sciences, Redeemer's University, Mowe, Ogun state, Nigeria. ${ }^{2}$ Centre for Lipid Research, Indian Institute of Chemical Technology, Hyderabad - 500 007, India. ${ }^{3}$ Industrial unit, Department of Chemistry, University of Ibadan, Ibadan, Oyo state, Nigeria.

\section{Authors' contributions}

AA: Contributed and participated in the design of the study. He carried out the synthesis of the methyl 9, 10-dihydroxyoctadecanoate and drafted the manuscript.

RO: Contributed in the design of the study.

BR: Contributed and participated in the design of the study and cosupervised it.

RP: Contributed in the design of the study and coordination. He also provided a laboratory space for the research work.

MN: Participated in the GC and GC-MS analysis.

All authors have read and approved the final manuscript.

\section{Competing interests}

The authors declare that they have no competing interests.

Received: 14 September 2011 Accepted: 6 December 2011 Published: 6 December 2011

\section{References}

1. Schwab AW, Bagby MO, Freeman B: Preparation and properties of diesel fuels from vegetable oils. Fuel 1987, 66:1372-1378.

2. Gervasio GC: Fatty Acids and Derivatives from Coconut Oil. In Bailey's Industrial Oil \& Fat Products. Volume 5.. 5 edition. Edited by: Hui YH. John Wiley 1996:33-83

3. Khot SN, Lascala JJ, Can E, Morye SS, Williams Gl, Palmese GR, Kusefoglu SH, Wool RP: Development and application of triglyceride-based polymers and composites. J. Appl Polym Sci 2001, 82:703-723.

4. Burkill HM: In The useful plants of West Tropical Africa. Volume 5.. 2 edition. Royal botanical garden, Kew, Richmond; 2000:11-13.

5. Hu YH, Gao Y, Wang DN, Hu CP, Zhu S, Vanoverloop L, Randall D: Rigid polyurethane foam prepared from a rape seed oil based polyol. J Appl Polym Sci 2002, 84:591-597. 
6. Strocchi A, Bonaga G: Correlation between urea inclution compounds and conformational structure of unsaturated C18 fatty acid methyl esters. Chem Phys Lipids 1975, 15:87-94.

7. Lucy SH, Jer HL: Fractionation of urea-pretreated squid visceral oil ethyl esters. J Am Oil Chem Soc 2001, 78:473-476.

8. Tor $\mathrm{C}, \mathrm{Yi} \mathrm{H}$ : Polyunsaturated fatty acid concentrates from borage and linseed oil fatty acid. J Am Oil Chem Soc 2001, 78:485-488.

9. Gamez MN, Noriega RJA, Medina JLA, Ortega GJ, Monroy RJ, Toro VFJ, Garcia HS, Angulo O: Concentration of EPA and DHA from fish oil by hydrolysis and urea complexation. Food Res Int 2003, 36:721-727.

10. Udaya N, Wanasundara X, Shahidi F: Concentration of omega 3polyunsaturated fatty acids of seal blubber oil by urea complexation: Optimization of reaction conditions. Food Chem 1999, 65:41-49.

11. Kidwai M, Poonam M: Neat reaction technology: A green tool. Ind J Chem 2005, 45:2330-2336.

12. Welton T: Ionic liquids in Green Chemistry. Green Chem 2011, 13:225-225.

13. Adewuyi A, Oderinde RA, Ajayi IA: The Metal Composition, Proximate Properties and the Effect of Refining on the Physico-Chemical Characterization of Baphia nitida and Gliricidia sepium Seed and Seed Oil. J Food Technol 2009, 7:43-49.

14. AOAC: In Official Methods of Analysis. Volume 67.. 14 edition. Association of Official Analytical Chemists, Arlington, VA; 1994.

15. Christie WW: Lipid analysis. 2 edition. Pergamoon press, Oxford; 1982, 107-130.

16. Oderinde RA, Ajayi IA, Adewuyi A: Evaluation of the mineral nutrients, characterization and some possible uses of Blighia unijugata bak seed and oil. Seed Science and Biotechnology 2008, 2:79-82.

doi:10.1186/1752-153X-5-79

Cite this article as: Adewuyi et al: Solvent free hydroxylation of the methyl esters of Blighia unijugata seed oil in the presence of cetyltrimethylammonium permanganate. Chemistry Central Journal 2011 $5: 79$

\section{Publish with ChemistryCentral and every scientist can read your work free of charge \\ "Open access provides opportunities to our colleagues in other parts of the globe, by allowing anyone to view the content free of charge." \\ W. Jeffery Hurst, The Hershey Company.}

- available free of charge to the entire scientific community

- peer reviewed and published immediately upon acceptance

- cited in PubMed and archived on PubMed Central

- yours - you keep the copyright

Submit your manuscript here:

http://www.chemistrycentral.com/manuscript/<smiles>c1ccccc1</smiles> 